\title{
Post-ERP pancreatitis as a model for cytokine induced acute phase response in acute pancreatitis
} H Messmann, W Vogt, A Holstege, G Lock, A Heinisch, A von Fürstenberg, H G Leser,
H Zirngibl, J Schölmerich

\begin{abstract}
Background/Aims-By contrast with animal models, in most cases it is not possible to examine the systemic response in patients in the first hours after onset of acute pancreatitis. The aim was to determine whether endoscopic retrograde cholangiopancreaticography (ERP)-induced pancreatitis can be used as a human model for the study of cytokine release and acute phase response in the first hours of the disease.
\end{abstract}

Patients and methods-Seventy consecutive patients undergoing ERP for different reasons were prospectively evaluated by sampling blood before and $0,1,4,12,24$, and 48 hours after ERP and, in patients who developed an acute post-ERP pancreatitis, daily until $C$ reactive protein (CRP) was within normal range. $A$ postERP pancreatitis was defined as a threefold increase of amylase or lipase and at least two of the clinical symptoms: abdominal pain, nausea, vomiting, and peritonism during 24 hours after ERP.

Results-Nine out of 70 patients developed an acute pancreatitis. Cytokines and other biochemical variables were measured in those nine and in 34 patients out of the 61 not developing pancreatitis. In the nine patients amylase and lipase increased within the first hour after ERP with maximum values between four and 12 hours. Interleukin-6 increased to maximal concentrations after 24-48 hours and the highest CRP concentrations were found 72 hours after ERP. Tumour necrosis factor did not change.

Conclusion-Post-ERP pancreatitis is an ideal model in which to examine the initial cytokine and acute phase response in the first hours after the initiation of the disease.

(Gut 1997; 40: 80-85)

Keywords: pancreatitis, cytokines, interleukin-6, $\mathrm{C}$ reactive protein, tumour necrosis factor.

The pathophysiology and mechanism of acute pancreatitis are complex and humoral and cellular interactions are involved in the network of the proteolytic induced pathomechanism.

Acute pancreatitis ranges from mild to extremely severe disease with multiple organ failure and fatal outcome. ${ }^{1}$ Once an acute pancreatitis has developed it is important to differentiate between patients with mild disease and those with a high risk for a severe outcome. ${ }^{2}$ Several prognostic indices mainly based on laboratory data - for example, the scoring system of Ranson et $a l^{3}$ - have been suggested as methods of detecting high risk patients. Granulocyte elastase,$^{45}$ protease inhibitors, ${ }^{6}$ acute phase proteins such as C reactive protein (CRP), ${ }^{789}$ or cytokines such as interleukin 6 (IL-6) ${ }^{10-12}$ are potential serum markers to assess the prognosis in acute pancreatitis. We have also shown a close relation between the concentrations and the time courses of serum IL- 6 and CRP, suggesting that during this inflammatory condition IL-6 is the main inducer of acute phase protein synthesis in humans. ${ }^{10}$

A major disadvantage of all studies examining the pathophysiology of acute pancreatitis in humans is the delay between the start of symptoms and admission to hospital. Therefore no data during the initiation phase of acute pancreatitis are available to describe exactly the time course of cytokine release and acute phase response in humans.

The aetiology of acute pancreatitis can be very different, but the concurrent acute phase response is uniform and is dependent on the severity of the disease. Using endoscopic retrograde cholangiopancreaticography (ERP) induced pancreatitis as a model for early acute pancreatitis it was possible for the first time to describe the acute phase response of acute pancreatitis in humans from the onset of the disease. Acute pancreatitis is a major complication of ERP. An increase of amylase after ERP is found in about $25 \%-75 \%$ of patients. ${ }^{13-16}$ Increases in pancreatic enzymes after ERP that are not associated with symptoms are generally considered unimportant. ${ }^{17}$ The frequency of post-ERP pancreatitis in most prospective studies is $5-10$ (extreme ranges $0.0-39.0) \%$, depending on several factors including operator experience, presence of acinar filling, the volume and osmolarity of the contrast medium, ${ }^{18}$ and the indication for ERP.

With this background we have tried to answer the questions:

(1) Is there a difference in lipase, amylase, IL-6, and CRP release after ERP in patients developing or not developing pancreatitis?

(2) How long is the time delay for IL-6 and CRP release into the peripheral circulation after ERP and after onset of the first clinical symptoms?

(3) Is an increase in IL-6 always followed by an acute phase protein increase and does IL-6 only increase in patients developing acute pancreatitis? 


\section{Methods}

PATIENTS

Seventy consecutive patients admitted for ERP to the endoscopy unit of the Department of Internal Medicine I of the University of Regensburg for different reasons were prospectively studied by sampling blood before and at given times after ERP. The examinations (45 diagnostic and 25 therapeutic procedures) were performed with a duodenoscope (Olympus JF 100, TJF 100, Hamburg, Germany) after premedication with midazolam (Roche, Grenzach-Wyhlen, Germany) and pethidine (Hoechst, Frankfurt, Germany) and relaxation of the duodenum with butylscopolamine (Boehringer, Mannheim, Germany) or glucagon (Lilly, Bad Homburg, Germany). The contrast medium was injected under fluoroscopic control. No antibiotic prophylaxis was given.

Samples from 27 patients not developing pancreatitis or worsening of their existing or chronic relapsing pancreatitis after ERP were not used for cytokine analysis because of increases in CRP before or immediately after ERP due to an acute biliary or alcoholic pancreatitis $(n=9)$, acute relapse of chronic pancreatitis $(n=6)$, acute or chronic cholangitis $(n=7)$, or other inflammatory diseases (for example, pneumonia) $(n=5)$. The remaining 43 patients were divided into three groups according to diagnosis on ERP - namely, patients with normal pancreatogram $(n=27)$, with chronic pancreatitis $(n=11)$, or with a pancreatic tumour $(n=5)$ (Fig 1).

A post-ERP pancreatitis was defined as a threefold increase of amylase or lipase and at least two clinical symptoms (upper abdominal pain, backache, nausea, vomiting, tenderness) during 24 hours after ERP. Nine patients developed post-ERP pancreatitis and their samples were analysed and compared with those of the 34 of the 70 patients not developing acute pancreatitis.

\section{CLINICAL ASSESSMENT}

All patients were assessed clinically daily for at least 48 hours; the nine patients with a postERP pancreatitis were assessed until they were free of symptoms, but at least for one week.
LABORATORY METHODS

Blood samples were taken before ERP and 0, $1,4,12,24$, and 48 hours after ERP in all 70 patients, and in patients who developed an acute post-ERP pancreatitis, daily until CRP was within normal range. Samples from 43 patients were used for analysis while the 27 with initially raised CRP were discarded.

Amylase was measured by an enzymatic colour test (Boehringer Mannheim $\mathrm{GmbH}$ Diagnostica, Mannheim, Germany) with normal values $<120 \mathrm{U} /$. Lipase was determined by turbidimetry using UV light (Boehringer). Normal values were set at $<190$ U/1. CRP was measured using an immunological turbidimetric test (Boehringer) with normal values of $<5 \mathrm{mg} / \mathrm{l}$. The serum concentrations of IL- 6 were measured by an enzyme linked immunosorbent assay (ELISA; Quantikine R and D Systems Inc, Minneapolis, USA). The minimum detectable dose was 0.70 $\mathrm{pg} / \mathrm{ml}$, the normal serum IL-6 concentration was $<10 \mathrm{pg} / \mathrm{ml}$, and the coefficient of variation (CV) was $<4.4 \%$. Tumour necrosis factor (TNF) was also measured by an ELISA (Medgenix, Ratingen, Germany) with a minimum detectable concentration of $3 \mathrm{pg} / \mathrm{ml}$ and a CV $<5.2 \%$ (a normal serum TNF concentration of $<20 \mathrm{pg} / \mathrm{ml}$ ).

\section{DATA ANALYSIS}

Data are expressed as median with ranges. Correlations were calculated by using linear regression grades and estimating the coefficient of correlation. Statistical analysis was by two tailed Mann-Witney $U$ test using the statistical software of Sigma Stat (Version 1.0, Jandel Corporation). Significance was set at $\mathrm{p}<0 \cdot 05$.

\section{Results}

Nine of the 70 patients $(12.9 \%)$ developed an acute pancreatitis as defined above. In eight patients the pancreatitis was mild and one patient developed a severe necrotising pancreatitis. One of these nine patients had signs of a chronic pancreatitis on ERP whereas the others showed a normal pancreatogram. The remaining 34 patients used for analysis had pancreatic tumour $(n=5)$, chronic pancreatitis $(n=10)$, and normal findings $(n=19)$ in ERP (Fig 1). Patients with post-ERP pancreatitis

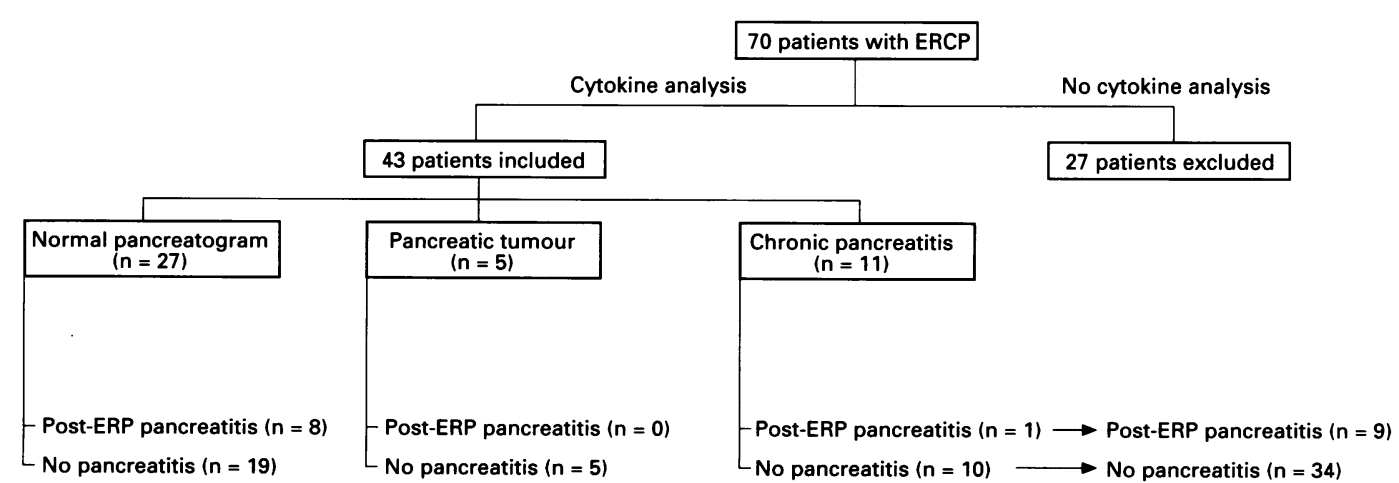

Figure 1: Breakdown of 70 patients examined consecutively with ERP. 


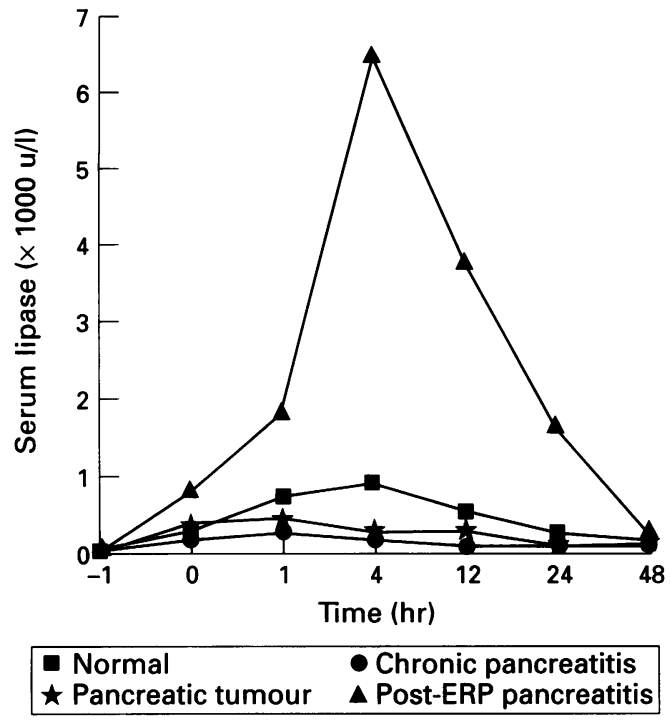

Figure 2: Lipase serum concentrations (median) during 48 hours after ERP in patients not developing pancreatitis with normal pancreas $(n=19)$, chronic pancreatitis $(n=10)$ or pancreatic tumour $(n=5)$ and in patients with post-ERP pancreatitis $(n=9)$. Time point 0 hour was defined as the end of the ERP procedure.

were all treated as inpatients and were in hospital for a median of 13 (range 8-20) days.

LIPASE, AMYLASE, CRP, IL-6, AND TNF AFTER ERP Peak values for lipase and amylase occurred one to four hours after ERP and were within normal ranges after 24-48 hours for the 27 patients with normal ERP, chronic pancreatitis, and pancreatic tumours not developing pancreatitis, whereas in those patients developing an acute post-ERP pancreatitis lipase and amylase were within normal ranges after 48-72 hours respectively (96 hours for the patient with necrotising pancreatitis) (Fig 2).

In five out of 29 patients with a normal pancreatogram and no signs of ERP induced pancreatitis IL-6 increased without an increase

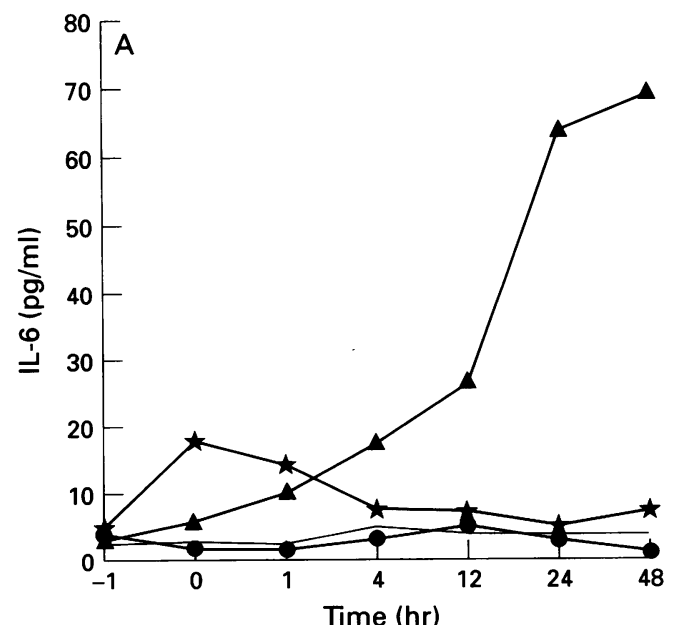

in CRP. All patients with post-ERP pancreatitis $(n=9)$ first developed an increase in IL-6 followed by an increase in CRP. However, the five patients with pancreatic tumours and no ERP induced pancreatitis showed slightly increased IL-6 $(<20 \mathrm{pg} / \mathrm{ml})$ and CRP $(<10 \mathrm{mg} /$ 1) values which did not change significantly after ERP.

In those patients developing post-ERP pancreatitis, IL-6 concentrations increased significantly between $12-48$ hours and peaked at 48 hours whereas CRP peaked 72 hours after ERP. TNF showed no changes (Fig 3 and Fig 4A).

For the patient with necrotising pancreatitis IL-6 $(565 \cdot 2 \mathrm{pg} / \mathrm{ml})$ peaked by 24 hours after ERP and CRP $(227.0 \mathrm{mg} / \mathrm{l})$ peaked 48 hours later; TNF did not change over time (Fig 4B).

Figure 5 shows the peak values of IL- 6 and CRP for all patients.

Maximal serum concentrations of IL-6 at days 1-7 correlated with the maximal serum concentrations of CRP in all patients with postERP pancreatitis $(r=0 \cdot 83 ; \mathrm{p}=0.00199 ;$ Fig 6$)$.

TIME DELAY OF LIPASE, AMYLASE, CRP, AND IL-6 RELEASE AFTER ERP AND FIRST CLINICAL SYMPTOMS IN PATIENTS WITH POST-ERP PANCREATITIS

First clinical symptoms indicating a post-ERP pancreatitis were detected at a median of 4.5 (3-7) hours after ERP whereas a more than threefold increase of IL- 6 and CRP occurred by $3.9(0-12)$ hours and $23 \cdot 1(4-72)$ hours after ERP respectively (Table).

All patients with a post-ERP pancreatitis except one had a more than threefold increase of lipase (median 6.5 (range 1.3 to 43 -fold increase) immediately after ERP (time 0), which was significantly higher than in patients with post-ERP pancreatitis ( $p=0.0145$; Fig 2$)$. Amylase also showed a significant increase immediately after ERP in patients with postERP pancreatitis compared with the remaining patients $(p=0.0026)$.

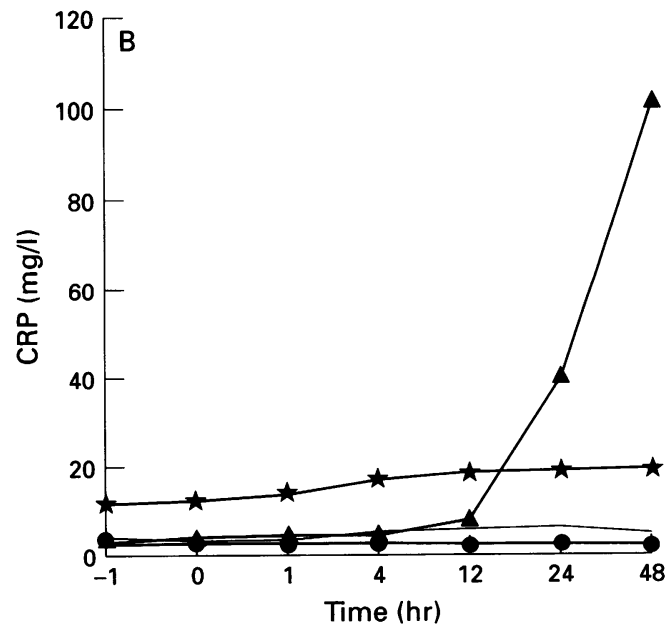

Figure 3: Serum concentrations of $(A) I L-6$ (normal $<10 \mathrm{pg} / \mathrm{ml})$ and $(B) C R P$ (normal $<5 \mathrm{mg} / \mathrm{l})$ (median) during 48 hours after ERP in patients with a normal pancreas $(n=19)$, chronic pancreatitis $(n=10)$ or pancreatic tumour $(n=5)$ and in patients with post-ERP pancreatitis $(n=9)$. Time point 0 hour was defined as the end of the ERP procedure. 


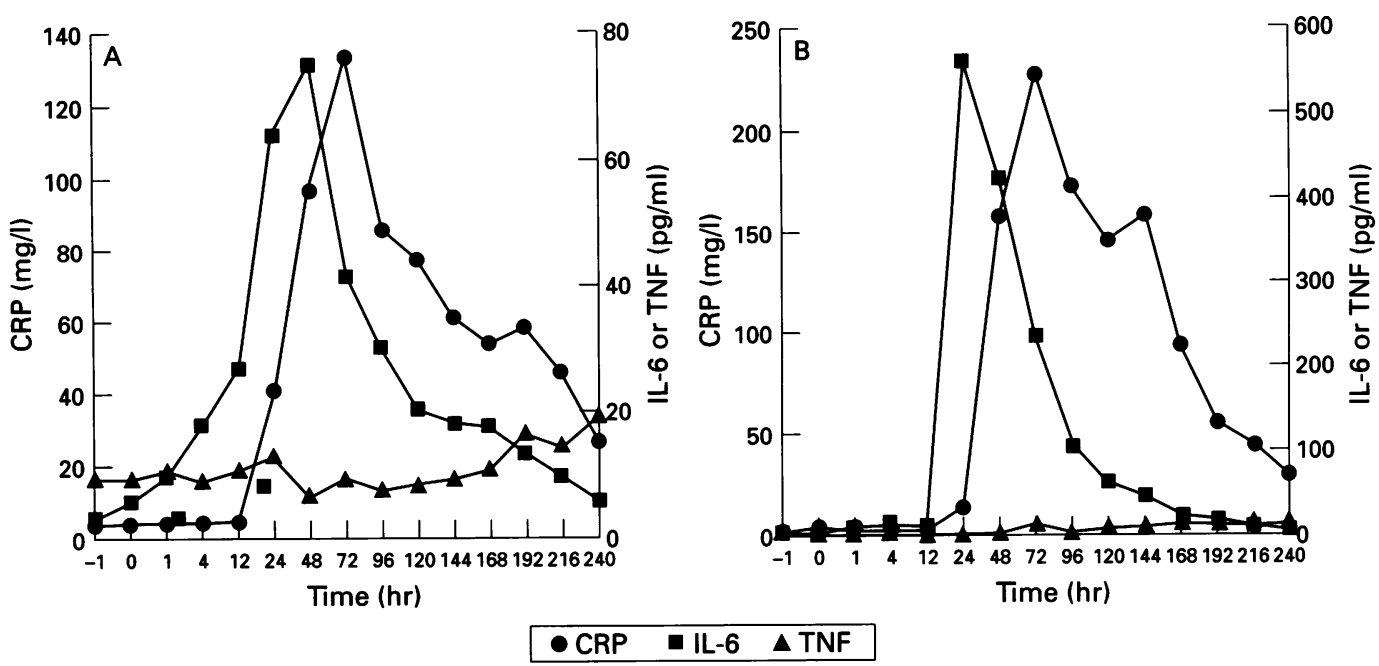

Figure 4: Serum concentrations (median) of CRP (normal $<5 \mathrm{mg} /$ ), IL-6 (normal $<10 \mathrm{pg} / \mathrm{ml}$ ), and TNF (normal $<20$ $\mathrm{pg} / \mathrm{ml}$ ) during 240 hours after ERP in $(A) 8$ patients with mild post-ERP pancreatitis and $(B)$ in a patient with severe (necrotising) post-ERP pancreatitis. Time point 0 hour was defined as the end of the ERP procedure.
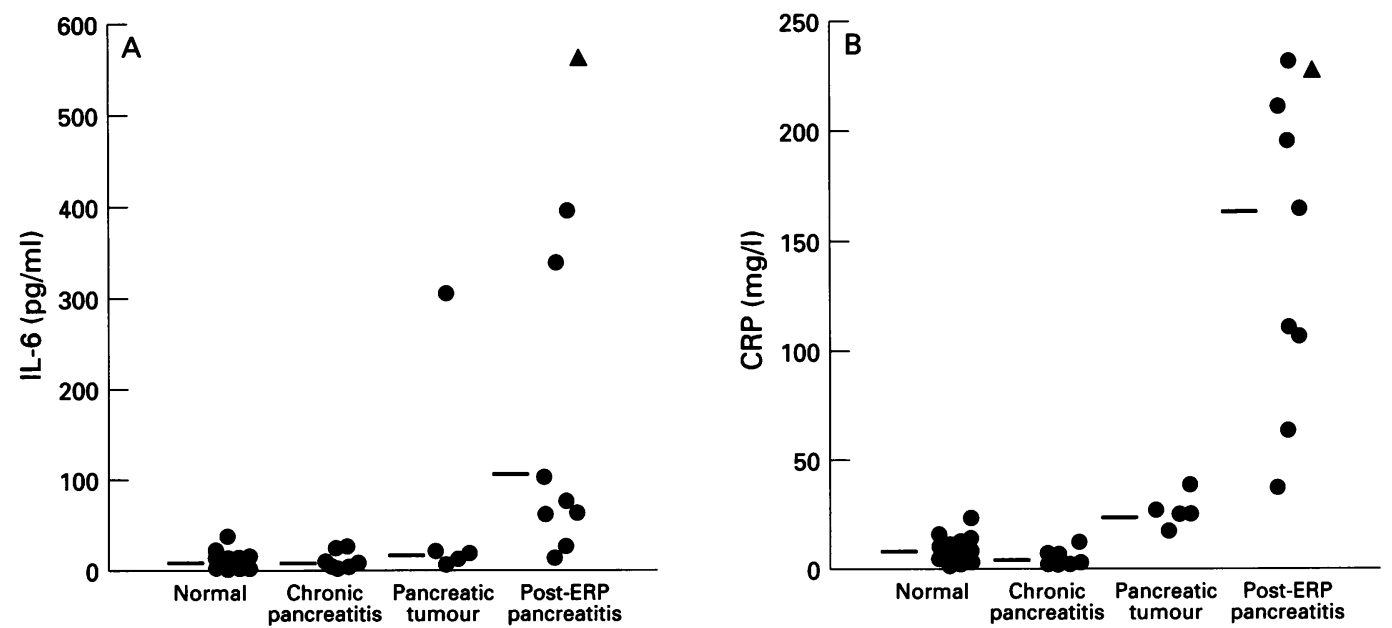

Figure 5: Peak serum concentrations of (A) IL-6 (normal $<10 \mathrm{pg} / \mathrm{ml}$ ) and (B) CRP (normal $<5 \mathrm{mg} /$ ) after ERP in patients with and without post-ERP pancreatitis. $\Delta$ Represents patient with a necrotising pancreatitis. - Represents median IL-6 and CRP concentrations. There is a significant difference between CRP and IL-6 serum concentrations of patients with post-ERP pancreatitis and patients with normal pancreatogram ( $p<0.0001$ and $p<0.0001$ respectively) or chronic pancreatitis ( $p<0.0001$ and $p<0.0001$ respectively) or pancreatic tumour (NS and $p<0.0026$ ).

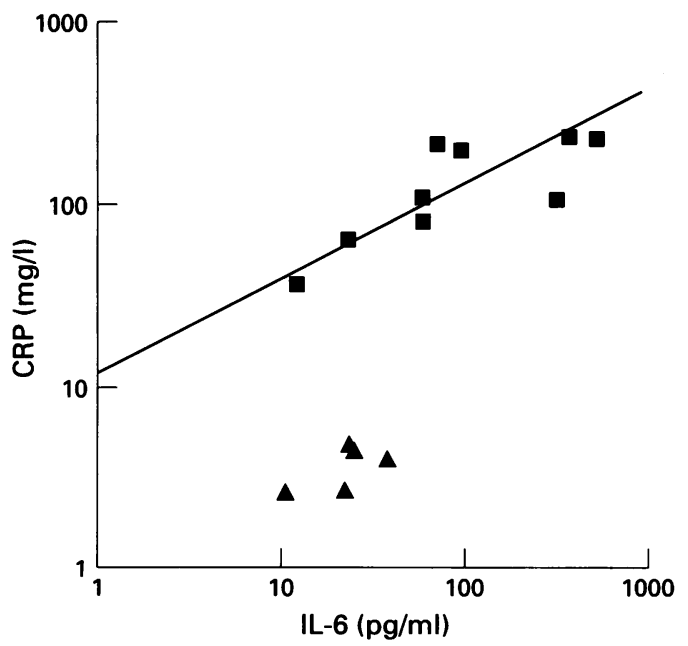

$\Delta$ IL-6 increase without post-ERP pancreatitis $(n=5)$ - Post-ERP pancreatitis $(n=9)$

Figure 6: Serum IL-6 concentrations and corresponding peak $C R P$ concentrations in patients with $(n=9)$ and without $(n=5)$ post-ERP pancreatitis (five of 19 patients with normal pancreatogram and 10 patients with chronic pancreatitis). The correlation was calculated from those patients with post-ERP pancreatitis only.
PREDICTIVE VALUE OF IL-6 FOR DEVELOPMENT OF PANCREATITIS

In all patients with acute post-ERP pancreatitis an increased IL-6 value was followed by an increased CRP. However, five out of the 29 patients with no signs of a post-ERP pancreatitis had increased IL-6 concentrations (mean 29.2 (SD $6.4 \mathrm{pg} / \mathrm{ml}$ ) which were not followed by a CRP peak (mean 3.5 (SD $0.5 \mathrm{mg} / \mathrm{l}$ ). The remaining 24 patients did not have increased IL-6 or CRP (Fig 6).

\section{Discussion}

It has been proposed that in acute pancreatitis there is an activation of inflammatory cells resulting in the release of inflammatory mediators responsible for a severe course of the disease. ${ }^{19}$ In a previous report ${ }^{10}$ we provided evidence that serum IL-6 concentrations precede acute phase response and reflect severity in acute pancreatitis.

However, neither this study nor other data describe the early onset of acute pancreatitis with regard to clinical symptoms and to the 
Maximal amylase, lipase, CRP, and IL-6 serum concentrations compared with time of first symptoms after ERP in patients with ERP induced pancreatitis

\begin{tabular}{|c|c|c|c|c|c|}
\hline $\begin{array}{l}\text { Patient } \\
\text { No }\end{array}$ & $\begin{array}{l}\text { Maximal amylas } \\
\text { Un) (time) } \\
n<120 \mathrm{Un}\end{array}$ & $\begin{array}{l}\text { Maximal lipas } \\
(U / D) /(\text { time }) \\
n<180 \mathrm{U} /\end{array}$ & $\begin{array}{l}\text { Maximal CRP } \\
(m g / l) /(\text { time }) \\
n<5 \mathrm{mg} / \mathrm{ml}\end{array}$ & $\begin{array}{l}\text { Maximal IL-6 } \\
(\mathrm{pg} / \mathrm{ml}) /(\mathrm{time}) \\
n<10 \mathrm{pg} / \mathrm{ml}\end{array}$ & $\begin{array}{l}\text { Time of first } \\
\text { symptoms } \\
\text { after ERP (hr) }\end{array}$ \\
\hline $\begin{array}{l}1 \\
2 \\
3^{\star} \\
4 \\
5 \\
6 \\
7 \\
8 \\
9\end{array}$ & $\begin{array}{c}803(24 \mathrm{hr}) \\
1650(12 \mathrm{hr}) \\
2680(4 \mathrm{hr}) \\
660(4 \mathrm{hr}) \\
3311(4 \mathrm{hr}) \\
2070(1 \mathrm{hr}) \\
1837(4 \mathrm{hr}) \\
154(12 \mathrm{hr}) \\
763(24 \mathrm{hr})\end{array}$ & $\begin{array}{c}5766(24 \mathrm{hr}) \\
7840(1 \mathrm{hr}) \\
18802(4 \mathrm{hr}) \\
3700(24 \mathrm{hr}) \\
22827(24 \mathrm{hr}) \\
9726(1 \mathrm{hr}) \\
13837(12 \mathrm{hr}) \\
557(12 \mathrm{hr}) \\
2004(12 \mathrm{hr})\end{array}$ & $\begin{array}{c}64 \cdot 1(72 \mathrm{hr}) \\
80 \cdot 9(168 \mathrm{hr}) \\
227 \cdot 0(72 \mathrm{hr}) \\
231 \cdot 1(48 \mathrm{hr}) \\
194 \cdot 4(96 \mathrm{hr}) \\
106 \cdot 7(72 \mathrm{hr}) \\
210 \cdot 0(72 \mathrm{hr}) \\
37 \cdot 3(96 \mathrm{hr}) \\
109 \cdot 6(96 \mathrm{hr})\end{array}$ & $\begin{array}{r}24 \cdot 1(48 \mathrm{hr}) \\
62 \cdot 1(48 \mathrm{hr}) \\
562 \cdot 2(24 \mathrm{hr}) \\
395 \cdot 5(12 \mathrm{hr}) \\
101 \cdot 2(24 \mathrm{hr}) \\
339 \cdot 6(24 \mathrm{hr}) \\
75 \cdot 0(48 \mathrm{hr}) \\
12 \cdot 2(24 \mathrm{hr}) \\
61 \cdot 0(48 \mathrm{hr})\end{array}$ & $\begin{array}{l}6 \\
4 \\
5 \\
3 \\
4 \\
4 \\
5 \\
6 \\
4 \\
7\end{array}$ \\
\hline
\end{tabular}

^Patient 3 had necrotising pancreatitis.

acute phase response. In the present study we have analysed clinical symptoms, serum concentrations of lipase and amylase, cytokine concentrations, and concentrations of the acute phase protein CRP using ERP induced pancreatitis as a human model.

Our overall $12.9 \%$ incidence of acute pancreatitis in 70 patients studied prospectively seems to be disproportionally high compared with other series. ${ }^{18}$ Several reasons may explain this. Firstly, most cases of ERP induced pancreatitis follow a mild and harmless course and therefore are often incorrectly interpreted or overlooked, especially if patients are examined as outpatients or quickly transferred back to the referring hospital. Secondly, most of the studies were retrospective, which raises problems of correct data recording. Using nearly the same criteria for definition of post-ERP pancreatitis as La Ferla et al ${ }^{17}$ our complication rate of $12.9 \%$ was similar to the $11.3 \%$ of that series. In a recent retrospective multicentre study on nearly 2000 patients ERP induced pancreatitis was diagnosed in up to $11 \cdot 2 \%$ for therapeutic and $9 \cdot 1 \%$ for diagnostic ERP. ${ }^{20}$

Compared with other studies ${ }^{14-17}$ our data confirm the increases of amylase and lipase within the first four hours and their return to normal values within 48 hours in patients without ERP induced pancreatitis. By contrast, patients with a post-ERP pancreatitis showed normal values within 72 hours (96 hours for the patient with necrotising pancreatitis). Similar results were described by La Ferla et $a l,{ }^{17}$ who found a significant higher amylase two hours after ERP in patients developing pancreatitis than in patients with no signs of an acute pancreatitis.

The initial cytokine response after ERP has not been studied before. Heath et al ${ }^{12}$ examined the delay between the onset of symptoms and peak IL-6 and CRP concentrations. However, one major disadvantage in that study was the time delay between first clinical symptoms and admission to hospital. Therefore, the time difference between onset of first clinical symptoms and IL-6 and CRP serum concentrations can only be estimated.

We also showed a time delay of several hours (median 4.5 hours) between the injury of the pancreas caused by the ERP and the time of first symptoms.

With our post-ERP pancreatitis model we were able to examine the blood samples and clinical symptoms at exact times before and at the very beginning of acute pancreatitis. In all patients developing an acute pancreatitis IL-6 release was followed by a CRP increase $24-48$ hours later (Fig 3). While the patient with the necrotising pancreatitis had the IL- 6 peak by 24 hours (Fig 3B), in the patients with mild pancreatitis this was delayed to 48 hours after ERP (Fig 3A). Therefore it is possible that the severity of the disease is not only reflected by higher but also earlier peaking IL-6 serum concentrations. These findings contrast with those of Viedma $e t a^{11}$ and Heath et $a l^{12}$ who found increased IL-6 serum concentrations in patients with necrotising pancreatitis, but not in patients with mild pancreatitis. This may be due to a more sensitive EILSA for IL-6 measurement, with a detection limit of $0.7 \mathrm{pg} /$ $\mathrm{ml}$ in our study compared with $150 \mathrm{pg} / \mathrm{ml}$ in earlier studies. Furthermore we showed, using this more sensitive ELISA, a similar IL-6 release in patients with mild pancreatitis compared with a patient with necrotising pancreatitis, but with a delayed and smaller IL-6 peak. More patients with severe and mild forms of pancreatitis need to be studied to confirm this. In all patients the CRP peak occurred between 48-72 hours after ERP.

Considering a time delay of four to five hours between pancreatic injury by ERP and first clinical symptoms we found an earlier peak of IL-6 than did Viedma et al, ${ }^{11}$ who measured the IL-6 peak 48-72 hours after the first clinical symptoms, and Heath et al ${ }^{12}$ found a peak after 36 hours in patients with necrotising pancreatitis. However, the time delay between IL-6 peak and CRP peak was nearly the same as our study. Other groups ${ }^{21} 22$ examined the IL-6 response after elective surgical interventions and found an early peak of IL-6, within 24 hours after operation. This is similar to our findings, probably because these groups could also determine the time of organ injury exactly.

By contrast with other reports, some of the patients with mild pancreatitis had CRP concentrations above $120 \mathrm{mg} / \mathrm{l}$. This might be because more samples were measured than is usual in clinical practice.

We confirmed an already reported ${ }^{10} 12$ correlation $(r=0.83)$ between IL- 6 and CRP peaks in acute pancreatitis.

Fourteen patients with an abnormal pancreatogram and 10 patients with chronic pancreatitis had neither an IL-6 nor a CRP increase, indicating that ERP without complications is usually not followed by an acute phase response. However, in five patients with a normal pancreatogram IL-6 increased significantly but was not followed by a CRP increase or clinical signs of acute pancreatitis. These findings contrast with those of Viedma et $a l^{11}$ who found increased concentrations of CRP without increased IL-6 values in patients with mild pancreatitis; this difference could also be because we used a more sensitive ELISA to measure serum IL- 6 concentrations. Whether IL-6 is directly responsible for induction of CRP production cannot be completely answered by our study. Figure 6 shows a correlation between IL- 6 and CRP in patients 
with post-ERP pancreatitis, so it is possible. The fact that in five patients IL- 6 but not CRP was raised indicates that there might be a threshold concentration of IL-6 for induction of CRP procuction rather than other factors influencing CRP release in these patients. It is known from both animal and human studies that IL-6 is the main inducer of acute phase protein synthesis in hepatocytes. ${ }^{10}$

The importance of TNF in acute pancreatitis is controversial. Our findings that TNF was not increased in our patients, mostly with mild pancreatitis, accord with other reports. Increases of TNF have mostly been described in cases of severe acute pancreatitis. ${ }^{23} 24$ Pajaanen $e t a l^{25}$ found the highest TNF values on the first day of admission, but these exceeded the detectable concentration in only $9 \%$ of the patients. Norman et al found a correlation between severity of pancreatic damage and TNF concentration, ${ }^{26}$ which might explain why no increases in TNF could be measured in our patients.

In conclusion, our data showed that postERP pancreatitis is an ideal model to examine the early onset of acute pancreatitis in humans. We have shown for the first time that injury to the pancreas is followed with a relatively uniform delay by clinical symptoms and that IL-6 release appears earlier than previous studies have suggested from retrospective analysis. However, there is agreement in the time delay between IL- 6 and CRP release. The pattern of release of IL-6 seems to be similar for mild and severe pancreatitis but, with a difference in time of peak and absolute IL- 6 serum concentrations. Release of IL-6 is not always followed by an increase in CRP; however, in those patients with an ERP induced pancreatitis all patients had raised IL- 6 values followed by increased CRP values.

1 Pitchumoni CS, Agarwal N, Jain NK. Systemic complications of acute pancreatitis. Am $\mathcal{F}$ Gastroenterol 1988; 83: cations of

2 Schölmerich J, Heinisch A, Leser HG. Diagnostic approach to acute pancreatitis: diagnosis, assessment of etiology and prognosis. Hepatogastroenterol 1993; 40: 531-7.

3 Ranson JHC, Rifkind KM, Roses DF, Fink SD, Eng K, Spencer FC. Prognostic signs and the role of operative management in acute pancreatitis. Surg Gynecol Obstet 1974; 139: 69-80

4 Groß V, Schölmerich J, Leser HG, Salm R, Lausen M, Rückauer $\mathrm{K}$, et al. Granulocyte elastase in assessment of severity of acute pancreatitis. Comparison with acutephase proteins C-reactive protein, $\alpha 1$-antitrypsin and protease inhibitor $\alpha 2$-macroglobulin. Dig Dis Sci 1990; 35: 97-105.

5 Uhl W, Büchler M, Malfertheiner P, Beger H. PMNelastase in comparison with CRP, antiproteases, and
$\mathrm{LDH}$ as indicators of necrosis in human acute pancreatitis. Pancreas 1991; 6: 253-9.

6 MacMahon M, Bowen M, Mayer A, Cooper E. Relation of $\alpha 2$-macroglobulin and other antiproteases to the clinical features of acute pancreatitis. Am $\mathcal{F}$ Surg $1984 ; 147$ : 164-70.

7 Mayer AD, McMahon MJ, Bowen M, Cooper EH. C reactive protein: an aid to assessment and monitoring of reactive protein: an aid to assessment and monito
acute pancreatitis. $f$ Clin Pathol 1984; 37: 207-11.

8 Pcute pancreatitis. $\mathcal{F}$ Clin Pathol 1984; 37: 207-11. C-reactive protein (CRP) and serum phospholipase A2 in the assessment of the severity of acute pancreatitis. Gut the assessment of

9 Wilson C, Heads A, Shenkin A, Imrie CW. C-reactive protein, antiproteases and complement factors as objective markers of severity in acute pancreatitis. $\operatorname{Br} \mathcal{F}$ Surg 1989; 76: 177-81.

10 Leser H-G, Gross V, Scheibenbogen C, Heinisch A, Salm R, Lausen $M$, et al. Elevation of interleukin- 6 concentration precedes acute-phase response and reflects severity in acute pancreatitis. Gastroenterology 1991; 101: 782-5.

11 Viedma JA, Pérez-Mateo $M$, Dominguez JE, Carballo $F$ Role of interleukin-6 in acute pancreatitis. Comparison wole of interleukin-6 in acute pancreatitis. Comparison 33: 1264-7.

12 Heath DI, CruickshankA, Gudgeon M, Jehanli A, Shenkin A, Imrie CW. Role of interleukin- 6 in mediating the acute phase protein response and potential as an early mean of severity assessment in acute pancreatitis. Gut 1993; 34 41-5.

13 Skude G, Whelin L, Maruyama T, Aryiama J. Hyperamylasaemia after duodenoscopy and retrograde cholangiography. Gut 1977; 18: 316-41.

14 Panthegini M, Pagani F, Alebradi O, Lancini G, Cestari R. Time course of changes in pancreatic enzymes, isoenzymes and isoforms in serum after endoscopic retrograde cholangiopancreaticography. Clin Chem 1991; 37: grade cho $1602-5$.

15 Nemesánsky E, Tulassay Z, Papp J. Serum enzyme changes after endoscopic retrograde cholangio-pancreaticography/ ERCP/. Acta Hepato-astroenterologica 1978; 23: 228-32.

16 Fiøsne U, Waldum HL, Romslo L, Kleveland PM, Johnsen $\mathrm{H}$ Engerbretsen LF. Amylase, pancreatic isoamylase and lipase in serum before and after endoscopic pancreatography. Acta Med Scand 1986; 219: 301-4.

17 LaFerla G, Gordon S, Archibals M, Murray WR. Hyperamylasaemia and acute pancreatitis following endoscopic retrograde cholangiography. Pancreas 1985; 1: 160-3.

18 Sherman S, Lehman GA. ERCP- and endoscopic sphincterotomy-induced pancreatitis. Pancreas 1991; 6: sphincte.

19 Rinderknecht $H$. Fatal pancreatitis, a consequence of excessive leukocyte stimulation? Int $\mathcal{F}$ Pancreatol 1988; 3: 105-12.

20 Weiner GR, Geenen JE, Hogan WJ, Catalano MF. Use of corticosteroids in the prevention of post-ERPpancreatitis. Gastrointest Endosc 1995; 42: 579-83.

21 Nishimito N, Yoshizaki K, Tagoh H, Monden $M$ Kishimoto S, Hirano T, Kishimoto T. Elevation of serum interleukin-6 prior to acute phase proteins on the inflammation by surgical operation. Clin Immunol Immunpathol 1989; 50: 399-401.

22 Cruickshank AM, Fraser WD, Burns HJG, Van Damme J, Shenkin A. Response of serum interleukin-6 in patients undergoing elective surgery of varying severity. Clin $\mathrm{Sci}$ undergoing elective

23 Hughes CB, Gaber LW, Kotb M, Mohey el-Din AB Pabst M, Gaber O. Induction of acute pancreatitis in germ-free rats: Evidence of a primary role for tumor necrosis factor alpha. Surgery 1995; 117: 201-3.

24 Exley AR, Leese T, Holliday MP, Swann RA, Cohen J. Endotoxaemia and serum tumour necrosis factor as prognostic markers in severe pancreatitis. Gut 1992; 33: 1126-8

25 Paajanen H, Laato $M$, Jaakkola $M$, Pulkki K, Niinikoski J, Nordback I. Serum tumour necrosis factor compared with C-reactive protein in the early assessment of severity of acute pancreatitis. Br $\mathcal{f}$ Surg 1995; 82: 271-3.

26 Norman JG, Fink GW, Franz MG. Acute pancreatitis induces intrapancreatic tumor necrosis factor gene expression. Arch Surg 1995; 130: 966-70. 